\title{
Article
}

\section{Understanding Factors Relevant to Self- Injurious Behavior in a High-Risk Secure Psychiatric Sample Developing the Theory-Driven Measure of Self-Injurious Behavior Engagement}

Caton, Charlotte, Ireland, Jane Louise, Chu, Simon, Ireland, Carol Ann and Cramer, Rob

Available at http://clok.uclan.ac.uk/34684/

Caton, Charlotte, Ireland, Jane Louise ORCID: 0000-0002-5117-5930, Chu, Simon ORCID: 0000-0001-8921-4942, Ireland, Carol Ann ORCID: 0000-00017310-2903 and Cramer, Rob (2020) Understanding Factors Relevant to SelfInjurious Behavior in a High-Risk Secure Psychiatric Sample Developing the Theory-Driven Measure of Self-Injurious Behavior Engagement. Journal of Forensic Nursing . ISSN 1556-3693

It is advisable to refer to the publisher's version if you intend to cite from the work. http://dx.doi.org/10.1097/JFN.0000000000000307

For more information about UCLan's research in this area go to http://www.uclan.ac.uk/researchgroups/ and search for <name of research Group>.

For information about Research generally at UCLan please go to http://www.uclan.ac.uk/research/

All outputs in CLoK are protected by Intellectual Property Rights law, including Copyright law. Copyright, IPR and Moral Rights for the works on this site are retained by the individual authors and/or other copyright owners. Terms and conditions for use of this material are defined in the policies page. 


\section{FACTORS RELEVANT TO SELF-INJURIOUS BEHAVIOUR}

Understanding factors relevant to self-injurious behaviour in a high risk secure psychiatric sample: Developing the Theory driven Measure of Self-Injurious Behaviour Engagement

Charlotte Caton., Jane L. Ireland ${ }^{1}$, Simon Chu., Carol A. Ireland, Robert J. Cramer*. University of Central Lancashire, Preston, UK and Ashworth Research Centre, Mersey Care NHS Trust: UK.

*Department of Public Health Sciences, University of North Carolina at Charlotte, Charlotte, NC, USA.

${ }^{1}$ Corresponding author. Email: JLIreland1@uclan.ac.uk; University of Central Lancashire, Preston, UK, PR1 2HE; Tel: +44 1772201201. 
FACTORS RELEVANT TO SELF-INJURIOUS BEHAVIOUR

\begin{abstract}
A measure for the assessment of self-injurious behaviour is developed. Commencing with a Delphi comprised of 33 experts; detached experts (academics), experts by exposure (staff) and experts by experience (patients), the Theory-driven Measure of Self-Injurious Behaviour Engagement (TM-SIBE) is outlined. This is then examined in two samples; high secure psychiatric male patients $(n=76)$ and high secure psychiatric nursing staff $(n=100 ; 50$ men, 50 women). We predicted that all components of the Theory of Planned Behaviour (TPB) and the capacity, belongness and burdensomeness elements of the Interpersonal Psychological Theory of Suicidal Behaviour (IPTSB) would be confirmed as important inclusions. Results initially demonstrated the importance of including intention, perceived behavioural control, affect, capacity, burdensomeness. The role of environmental and individual factors, such as coping, were captured as additional variables of value. However, the structure of items differed between patients and staff. Being valued consistently represented a core consideration, as did capacity and affect. Directions for future research are indicated.
\end{abstract}

KEY WORDS: self-injurious behaviour; suicidal intent; Theory Planned Behaviour; IPTSB; high secure psychiatric sample; TM-SIBE. 


\section{FACTORS RELEVANT TO SELF-INJURIOUS BEHAVIOUR}

Understanding factors relevant to self-injurious behaviour in a high risk secure psychiatric sample: Developing the Theory driven Measure of Self-Injurious Behaviour Engagement

Self-injurious behaviour is a robust risk factor for suicide (e.g., Guan et al., 2012; Hawton \& Harriss, 2007; Klonsky et al., 2013). Consequently, exploring the factors that contribute to engagement in this is important. There is, arguably, a need to move away from reliance on record-based inquiry to determine risk factors, to capturing fully the views of those involved in such behaviour, either as detached experts (academics), experts by exposure (professional staff) or experts by experience (those engaging in self-injurious behaviour). Incorporating experts by experience has received particularly limited attention in the literature. This is particularly the case among vulnerable and higher risk groups, such as those with a history of psychiatric difficulties, where rates of suicide can be elevated (e.g., Mann et al., 2005; Crump et al., 2014).

\section{Extent of Self-Injury in Secure Psychiatric Settings}

Those detained in secure psychiatric settings, where diagnoses are complex and commonly involve co-morbidity, present with elevated rates of self-injury. White et al. (1999) and Gray et al. (2003) both report prevalence rates of around 50\% in their secure patient sample, with this also extending to higher secure psychiatric units (Daffern \& Howells, 2009). However, there remains a lack of attention to these more specialised clinical groups, particularly for men, where self-injurious behaviour is thought more severe in comparison to women, and where acts of self-harm are more readily dismissed by professionals (Green \& Jakupcak, 2015). Indeed, men have been found more likely to die by suicide following an incident of self-injury (Karasouli et al., 2015), making their inclusion in research essential.

\section{Understanding Self-Injurious Behaviour and the Contribution of Theory}




\section{FACTORS RELEVANT TO SELF-INJURIOUS BEHAVIOUR}

The need to account for the perspectives of those engaging in self-injurious behaviour in understanding self-injurious behaviour has increasingly been recognised (Lewis \& Hasking, 2019), particularly among higher risk samples, such as forensic and psychiatric samples (e.g., Garbutt \& Casey, 2015; Ireland \& Quinn, 2007). In exploring this area, attention can valuably be placed on the Theory of Planned Behaviour (TPB: Ajzen, 1991). This outlines how the most important predictor of whether an individual engages in certain behaviours represent their "behavioural intentions". Intentions are predicted by three variables; "attitudes", namely positive or negative evaluations of the behaviour; "subjective norms", an individual's perception about relevant other's beliefs about the behaviour; and "perceived behavioural control", the perceived ease or difficulty of performing the chosen behaviour. TPB has been empirically supported across several health-related research domains, including self-injury (O'Connor et al., 2006). Research has, for example, captured application of this theory to the prevention of parasuicidal behaviour, with O'Connor and Armitage (2003) extending it to accommodate variables of "moral norms" (personal feelings or responsibility) and "anticipated affect" (how affect may impact on actions). In a sample of patients admitted to an acute psychiatric ward, O'Connor and Armitage demonstrated how all aspects of the TBP variables, including the additional factors of moral norms and anticipated affect, distinguished between those who self-injured and those who had not. TPB variables explained almost $50 \%$ of the variance associated with intention to self-injure, with moral norms explaining additional variance. Anticipated affect did not, however, contribute overall, which was surprising. The Emotional Cascade Model of Selby and Joiner (2009) certainly places emphasis on an individual being unable to manage an increasing intensity of emotions, promoted by cognitive rumination, and leading to reliance on behaviours that can promote a physical sensation to distract. Physical self-harm could form one such behaviour. 


\section{FACTORS RELEVANT TO SELF-INJURIOUS BEHAVIOUR}

In a later study, O'Connor et al. (2006) did find a role for affect, noting that affective attitude, perceived behavioural control, group identity, and descriptive norms were all significant predictors of intention to engage in self-injury. Importance of group identification and beliefs about self-injury from others (peers, friends, those around them) in influencing intention to self-injury were also identified as important considerations.

Lewis et al. (2011) further contributed to the potential application of TPB by focusing on one core aspect of affect - depressive symptoms - as well as the remaining TPB components, as predictors of self-injurious intent. All participants had a history of selfinjurious behaviour. Results demonstrated, unsurprisingly, that depressive symptoms were associated with a stronger intent to self-injure. Interestingly, however, viewing self-injury as more "acceptable" was associated with a greater intent to self-injure in the future. Lewis et al. also noted how, among those with a history of more frequent self-injury, the intent to selfinjure was uniquely predicted by favourable attitudes towards the behaviour. This suggested value in considering the role of attitudes in supporting self-injury, which represent a core contributing element of TPB and arguably are as important to consider as psychopathology (Morgan \& Priest, 1991).

\section{Attitudes and the Interpersonal Psychological Theory of Suicidal Behaviour}

In Theory of Planned Behaviour (TPB) terms, attitudes can represent a component of TPB in its own (individual) right or form part of social norms, both of which contribute to the decision-making underpinning intent to self-harm. Research conducted on general attitudes towards self-injury has focused on nurses. This has generally cited negative attitudes, antipathy and the perception of such patients as being less deserving of resources (e.g., Dickinson \& Hurley, 2012). However, the literature base is limited and required more detailed examination. 


\section{FACTORS RELEVANT TO SELF-INJURIOUS BEHAVIOUR}

By incorporating the wider social environment and how an individual is considered to integrate within this, attention can also be shifted to other well-supported theories underpinning self-injurious behaviour, namely the Interpersonal Psychological Theory of Suicidal Behaviour (IPTSB: Joiner, 2005; Joiner \& Van Orden, 2008). Here, “failed belongingness", "perceived burdensomeness" on others and "capacity to enact self-injury" begin to feature as particularly relevant, with the latter captured via a prior history of engagement in self-injurious behaviour (Joiner \& Van Orden, 2008). These components can translate well to staff attitudes, where patients who repeatedly self-harm can be viewed more negatively by some, can be considered a burden on resources and/or where staff feel a social disconnect from them (e.g., McAllister et al., 2002). However, negative attitudes appear informed by skill level, with McAllister et al. (2002) reporting attitudes from emergency nurses were less negative if they felt skilled.

Evidence of negative, as well as positive, beliefs towards those that self-harm are also indicated in staff from secure settings (Dickinson \& Hurley, 2012; Dickinson et al., 2009; Sandy \& Shaw, 2012). For example, Dickinson et al., (2009), report that attitudes of nurses and support workers for detained young people who engaged in self-injurious behaviour, comprised positive themes connected to sympathy and empathy but also antipathy from staff, judgement of behaviour as attention seeking, and evidence of client labelling. This has equally been extended to secure psychiatric settings, with Sandy and Shaw (2012) reporting that mental health nurses presented with mixed attitudes towards self-injury but that, overall, beliefs were negative. There is also indication of further factors impacting on the nature of expressed attitudes, with prison officers, for example, reporting negative attitudes towards self-harm but with this directed more toward those prisoners who were described as poorly behaved (Ireland \& Quinn, 2007).

\section{The Current Study}




\section{FACTORS RELEVANT TO SELF-INJURIOUS BEHAVIOUR}

Overall, there appears increasing acceptance that theories such as TPB and IPTSB make a valuable contribution in terms of explaining what potential variables could be critical in understanding the decision to self-harm. However, this has not yet been operationalised in a measure that could be used to capture expert views, or one that accounts for the wider aspects of the social environment, namely staff and patients. The current study aims to address this area by exploring the development of a theory-driven measure that accounts for the views of experts via a Delphi and, following this, the views of male patients detained in high secure psychiatric care and the nursing staff (men and women) who care for them. The research further explores if there is commonality between experts by exposure (staff) and experts by experience (patients). Aspects of TPB were predicted to be confirmed as valuable across all experts, specifically in relation to behavioural control, intention (O’Connor \& Armitage, 2003; O'Connor et al., 2006) and in highlighting the importance of attitudes (Dickinson \& Hurley, 2012; Dickinson et al., 2009; Lewis et al., 2011; Sandy \& Shaw, 2012). A role for affect was predicted to be evidenced (Selby \& Joiner, 2009) but less well defined (O’Connor et al., 2006). Capacity, belongingness and burdensomeness were all felt as likely important (Joiner, 2005; Joiner \& Van Orden, 2008). The structure of factors identified were predicted to differ between patients and staff.

\section{Study 1: Exploring Factors Relevant to Self-Injurious Behaviour - A Delphi Study}

This study explored the views of experts concerning the factors they considered relevant to an assessment of the likelihood of engaging in self-injurious behaviour. The aim was to reach consensus on specific items that could form part of a theory driven measure of self-injurious behaviour engagement, using TPB and IPTSB as its grounding theories.

\section{Method}


FACTORS RELEVANT TO SELF-INJURIOUS BEHAVIOUR

\section{Participants}

The expert criteria used were that participants should either be practitioners currently working with individuals who self-injure or academics who had published at least two papers in the last five years, in self-injurious behaviour. Thirty-three specialists (10\% response rate) from nine countries participated. Forty-two percent considered themselves practitioners, another $18 \%$ had published work about self-injury and the remaining $40 \%$ considered themselves both academic and practitioners.

\section{Procedure}

The research was approved by a University ethics panel. Experts were identified by a review of published literature and through an internet search for self-injury experts, which included expert witness directories. Publications were identified by searching MEDLINE and PsychINFO, using the keywords 'self-harm' and 'self-injury'.

\section{Approach to Measurement}

A Delphi is a structured communication technique where experts are asked to answer questions via a series of rounds. After each round, a summary of provided views are fedback to participants, who are then encouraged to revise their earlier answers, based on the responses of other members of the panel. The process ends when consensus or theoretical saturation is achieved (Skulmoski et al., 2007). The current study required three rounds to reach consensus. In round 1 experts were asked to propose questions that could be used to ascertain the presence of factors likely to affect engagement in self-injurious behaviour, with pre-identified components drawn from the Theory of Planned Behaviour and the capacity, burdensomeness and belongingness elements of IPTSB as a framework. Findings were analysed using grounded theory.

\section{Results}


Thirty-two items were initially suggested as important by experts in Round 1. Twentytwo participants who contributed in round one completed round two (67\% response rate) and 20 completed round three (91\% response rate). For each round they were invited to confirm or change their responses, following receipt of group feedback. Items finally included following round three had to reach a consensus of $80 \%$ agreement, namely with experts rating each item as 'essential' or 'important'. The $80 \%$ agreement level was based recommendations from Delphi research (Keeney et al., 2006). The final round produced 18 agreed items, presented in Table 1.

<Insert Table 1 here>

Table 1 presents the first version of the Theory-driven Measure of Self-Injurious Behaviour Engagement (TM-SIBE), with the final composition then explored in a sample of patients and staff in a high secure psychiatric setting, where the prevalence of self-injurious behaviour was considered raised (Daffern \& Howells, 2009).

\section{Study 2: Exploring the Theory-driven Measure of Self-Injurious Behaviour}

\section{Engagement (TM-SIBE) across Staff and Patients in High Secure Psychiatric Sample.}

This study aimed to explore the application of the TM-SIBE to a sample of experts by exposure (staff involved in self-injurious incidents) and experts by experience (patients).

\section{Method}

\section{Participants}


FACTORS RELEVANT TO SELF-INJURIOUS BEHAVIOUR

The patient sample comprised 76 adult men. All were detained in conditions of high security (mean age 38, range 23-65 years) under the provision of the Mental Health Act (UK). Ninety percent of the patient sample acknowledged a prior history of self-injurious behaviour. The staff sample comprised 100 ward-based psychiatric nursing staff (50 men and 50 women) from the same hospital.

\section{Measure}

All completed the Theory-driven Measure of Self-Injurious Behaviour Engagement (TM-SIBE: see Table 1). Patients were asked to answer the items, as applied to them, with staff considering how they would apply generally to patients who engaged in self-injurious behaviour. The items were rated on a Likert scale of 1 to 7 , with higher scores indicating higher endorsement.

\section{Procedure}

Patients were approached following clearance being given by their Responsible Clinician. Nursing staff were identified via the incident reporting system as having worked directly with an incident of self-injurious behaviour within the hospital. They were individually approached and consented

\section{Patient Results}

Reliability and Structure Analysis. The original 18 items produced an $\alpha=.75$ but with five items producing negative to item-total correlations. These were consequently removed, increasing the $\alpha$ to .87 . A factor analysis was subsequently conducted, using these 13 items. The Monte Carlo Parallel Analysis and a Scree plot indicated two factors. A principal axis factorial with Direct Oblim was consequently employed, restricted to items loading above .40 . This resulted in 12 items loading, with one item (It is in my control if I injure myself) failing to do so. Factor 1 comprised six items, was labelled "Increased capacity 
FACTORS RELEVANT TO SELF-INJURIOUS BEHAVIOUR

and positive belief in affective value of self-harm" ( $\alpha$ to .88). Factor 2 comprised six items, labelled "Intention to self-harm and feeling valued" ( $\alpha$ to .81). The factors are indicated in Table 2.

<Insert Table 2 here>

\section{Staff Results}

Confirming Structure. A confirmatory factor analysis was initially employed to determine if the two-factor structure indicated in the patient sample was applicable to staff. The initial model did not prove a good fit $\left(\mathrm{X}^{2}(53)=132.18, \mathrm{p}<.000 ; \mathrm{RMSEA}=.12\right.$; CFI: .60). The fit of a single factor was also explored, with the fit remaining poor $\left(X^{2}=145.05\right.$, $d f$ $=54, \mathrm{p}<.000 ;$ RMSEA $=.13 ;$ CFI: .54 Chi Square $=145.05, \mathrm{df}=54, \mathrm{p}<.000)$.

Consequently, the factor structure of the original 18 items (Table 1) were explored to determine if there was a more unique structure of the data when applied to staff. These 18 items produced a low $\alpha=.67$, with two items negatively correlating. Their removal did not have a notable impact on the alpha and they were consequently retained for the subsequent factor analysis. A Monte Carlo Parallel Analysis and Scree plot indicated three factors. A principal axis factorial with Direct Oblim, restricted to three factors and items loading above .40 , resulted in 14 items loading.

Factor 1 comprised six items and labelled "Patients in control, planning for and intending self-injurious behaviour" $(\alpha=.68)$; Factor 2 comprised four items, labelled "Being valued and coping effectively" ( $\alpha=.63)$; Factor 3 comprised four items, labelled "Capacity for self-injury and a role for affect” $(\alpha=.69)$. All alphas were acceptable accounting for the small number of items in each. The resulting three factors are indicated in Table 3, along with factor means. 
<Insert Table 3 here>

Analysis across sex using ANOVA indicated a significant effect for Factor $1(F=$ $7.23, \mathrm{df}=1,98, p=.008$ ), with women presenting with higher scores than men (means 13.7 vs 11.9). There were no sex differences for Factor $2(p=.48)$ or Factor $3(p=.66)$.

\section{Discussion}

Value was demonstrated in the application of the Theory of Planned Behaviour (TPB) in capturing factors relevant to explore in determining engagement in self-injurious behaviour. There was also clear evidence emerging for an extension of TPB to capture the anticipated affect element proposed by O'Connor and Armitage (2003) and the importance of including the capacity and burdensomeness elements of the IPTSB (Joiner, 2005; Joiner \& Van Orden, 2008). What became clear from the Delphi was a consensus that intention remains a critical element to capture, along with the perceived behavioural control component of TPB. This supported the prediction that behavioural control and intention are important. Behavioural control was linked to the ease by which the behaviour could be conducted. Although clearly forming part of the perceived behavioural component element, the aspect of ease was suggestive of an increased capacity to engage in such behaviour, thus also consistent with IPTSB and the prediction that capacity would emerge as relevant. The inclusion of past behaviour being relevant was further supportive of the IPTSB component of capacity, with items also emerging that related to feeling socially supported and valued. This was consistent with the IPTSB element of burdensomeness (or absence of). Although a social group appeared of some value, this was not explicitly linked to belongingness; rather, it appeared that burdensomeness was of more value. Factors external to the individual also 


\section{FACTORS RELEVANT TO SELF-INJURIOUS BEHAVIOUR}

appeared worthy of consideration. These factors generally fell outside TSB and IPTSB and included individual coping skills and the level of knowledge/insight that those engaging in self-injurious behaviour had concerning the factors underpinning their behaviour.

A clear emerging theme from the data analysis, however, represented a role of affect, originally described as anticipated affect by O'Connor \& Armitage (2003). This result was not wholly consistent with the prediction that the role for affect would be less well defined since there was considerable clarity indicated. For example, not only did the Delphi provide support for the role of affect, but also in relation to its function. Affect presented as both negatively reinforcing (i.e., offering relief from symptoms) or positively reinforcing (i.e., an emotion as a specific gain). This supported the role of affect as a key variable for consideration (O'Connor et al, 2006; Lewis et al, 2011) and one that arguably requires full integration into enquiries concerning self-injurious behaviour. This certainly fits with the Emotional Cascade Model (ECM: Selby \& Joiner, 2009), where dysregulated behaviours, such as self-injury, are used to distract from an intensifying experience of emotion. The importance of affect is certainly indicated in the current study. Affect appears a reinforcing component to the behaviour, and thus a critical component in terms of prevention and/or effective management. What is absent, however, is a role for cognition underpinning affect, a role that would be predicted by the ECM in the form of rumination. Cognition did not emerge as a factor in the current study. Nevertheless, it perhaps represents an area worthy of further focused attention, particularly regarding rumination (Selby \& Joiner, 2009).

Thus, the Delphi provided support for the perceived behavioural control aspect of intention (TPB) and the extension to capture anticipated affect (TPB), as well as a role for capacity and burdensomeness (IPTSB). There were further extensions indicated to capture individual variables, such as coping skills and the quality of the environment in providing support. The latter could, arguably, represent a simple extension of the IPTSB component of 


\section{FACTORS RELEVANT TO SELF-INJURIOUS BEHAVIOUR}

burdensomeness to others. However, what did not emerge from the Delphi was a clear role for the further components of the TPB, namely moral norms, attitudes and subjective norms. Attitudes, surprisingly, failed to emerge despite their relative dominance in the literature as key variables (Dickinson et al., 2009; McAllister et al., 2002; Morgan \& Priest, 1991; Sandy \& Shaw, 2012). This was also inconsistent with the prediction that attitudes would be important. Furthermore, social cognitions, surprisingly, did not dominate the final consensus, which was inconsistent with expectations from previous research (Lewis et al., 2011).

The ensuing analysis with the patient and staff sample revealed some interesting results that refined these earlier findings. As predicted, the structure of items differed between patients and staff. Patients focused on the increased capacity component of selfinjurious behaviour and the potential reinforcing aspects of self-harm in terms of affect. This provided support for the capacity element of IPTSB and TPB anticipated affect (O'Connor \& Armitage, 2003; O’Connor et al., 2006). Intention remained a core variable but was underpinned by the absence of protective factors and included a degree of affect. The inclusion of a social element as part of this factor shared clear similarity with the perceived burdensomeness component of IPTSB, focusing on the importance of feeling valued and not just the importance of a social group being present. Thus, belonging did not feature in the same way as feeling valued, with it speculated here that feeling valued would reduce your perception of being a burden on others.

Interestingly, control, as a component of perceived behavioural control, was not a feature with patients. This tentatively points to consideration of their actions as impulsive and, potentially, more affect driven in terms of dysregulation. This is more fitting with the expectations of the ECM (Selby \& Joiner, 2009). Although speculative, it does suggest a need to focus not just on affect and its anticipated impacts, but on the specific nature of affect and the level of control a patient considers they have over this. Staff, however, appeared to 


\section{FACTORS RELEVANT TO SELF-INJURIOUS BEHAVIOUR}

place more emphasis on patients being in control of their self-injurious behaviour, with planning and intention core aspects. This placed emphasis on the perceived control aspect of TPB, which had also emerged following the Delphi study but not within the patient sample. This suggests that when detached experts (academics) and experts by exposure (staff/practitioners) are asked, they reflect more on the amount of control a patient has. This could explain the emphasis on the perceived behavioural control aspect of TPB since this theoretical model was not devised using experts by experience (i.e. patients), whose emphasis appears more towards lack of control and affect as important.

There was also a sex difference that emerged with the staff group, with more women than men endorsing the factor 'patients in control, planning for and intending self-injurious behaviour'. This is worth noting since it could reflect an underlying attitudinal component that has not been captured, with sex differences certainly considered relevant to attitudes (Ireland \& Quinn, 2007). This is also a pertinent reminder of the clinical sample in this study, namely male patients, since it suggests differences with women patients could not be ruled out and perhaps represent a commendable direction for future study.

Nevertheless, there was some consistency in the patient and staff groups concerning item structure, most notably in relation to the concept of being valued and the importance of capacity. Regarding the former, for staff, value was contained in a factor that also included coping, whereas capacity for patients also include affect. Inclusion of capacity and affect again supports the expectations of IPTSB and the extended version of the TSB in relation to anticipated affect. The concept of value was, however, emerging again as a consistent feature across samples, further supporting inclusion of the IPTSB component of burdensomeness being accounted for. Despite some variation in the factor structure indicated between staff and patients, the results suggest some commonality in the factors viewed as important to 


\section{FACTORS RELEVANT TO SELF-INJURIOUS BEHAVIOUR}

inquire about with regards to self-injurious behaviour, namely capacity, intent and planning, affect, and feeling valued by others.

\section{Limitations and Future Research}

The study is not without its limitations. The clinical samples employed were moderate in size, which brings an unavoidable limitation in terms of generalising results. In addition, although a wider range of theories could have been drawn upon to develop the TM-SIBE, it would arguably be unmanageable to utilise too many and attempt to seek expert consensus, as was required with the Delphi method. Instead, the TPB and IPTSB were selected as the most commonly applied and over-arching theories. Nevertheless, value in further developing the TM-SIBE to account for additional theoretical components cannot be discounted and it would represent a useful direction for future research. A further direction for future research is clearly the application of the TM-SIBE to a population where self-injurious behaviour is raised and where associations with variables known to predict higher levels of self-injurious behaviour risk can be explored.

\section{Conclusion}

The Theory of Planned Behaviour has clear application to the area of self-injurious behaviour, particularly if extended to capture anticipated affect and the capacity and burdensomeness elements of the Interpersonal Psychological Theory of Suicidal Behaviour. Behavioural control and intention also presented as important considerations, alongside factors such as individual coping skills and the level of insight held by those engaging in self-injurious behaviour. An absence of control and a role for affect were primarily identified by the patient sample, whereas staff and academics appeared to focus more on having control to represent a defining feature of self-injurious behaviour. Attitudes were not, however, presenting as an element to consider, which represented an unexpected outcome. Overall, the studies 


\section{FACTORS RELEVANT TO SELF-INJURIOUS BEHAVIOUR}

demonstrated clear value in the application of theory to this important area of study, proposing a focus on the integration of existing theory, with some extension, to provide a more meaningful assessment of self-injurious behaviour.

\section{References}

Ajzen, I. (1991). The theory of planned behavior. Organizational Behavior and Human Decision Processes, 50(2), 179-211

Crump, C., Sundquist, K., Sundquist, J., \& Winkleby, M. A. (2014). Sociodemographic, psychiatric and somatic risk factors for suicide: A Swedish national cohort study. Psychological Medicine, 44(2), 279-289. https://doi.org/10.1017/S0033291713000810

Daffern, M., \& Howells, K. (2009). Self-harm and aggression in a dangerous and severely personality disordered patients of a high security hospital. Psychiatry, Psychology and Law, 16(1), 150-154. https://doi.org/10.1080/13218710802471156

Dickinson, T., \& Hurley, M. (2012). Exploring the antipathy of nursing staff who work within secure healthcare facilities across the United Kingdom to young people who self-harm. Journal of Advanced Nursing, 68(1), 147-158.

https://doi.org/10.1111/j.1365-2648.2011.05745.x

Dickinson, T., Wright, K. M., \& Harrison, J. (2009). The attitudes of nursing staff in secure environments to young people who self-harm. Journal of Psychiatric and Mental Health Nursing, 16(10), 947-951. https://doi.org/10.1111/j.1365-2850.2009.01510.x

Garbutt, K., \& Casey, H. (2015). Attitudes towards prisoners who self-harm scale: A psychometric evaluation. Journal of Aggression, Conflict and Peace Research, 7(3), 158-166. https://doi.org/10.1108/JACPR-08-2014-0133 
FACTORS RELEVANT TO SELF-INJURIOUS BEHAVIOUR

Gray, N. S., Hill, C., McGleish, A., Timmons, D., MacCulloch, M. J., \& Snowden, R. J. (2003). Prediction of violence and self-harm in mentally disordered offenders: A prospective study of the efficacy of HCR-20, PCL-R, and psychiatric symptomatology. Journal of Consulting and Clinical Psychology, 71(3), 443-451. https://doi.org/10.1037/0022-006X.71.3.443

Green, J., \& Jakupcak, M. (2015). Masculinity and men's self-harm behaviours: Implications for non-suicidal self-injury disorder. Psychology of Men and Masculinity, 17(2), 147155. https://doi.org/10.1037/a0039691

Guan, K., Fox, K. R., \& Prinstein, M. J. (2012). Nonsuicidal self-injury as a time invariant predictor of adolescent suicide ideation and attempts in a diverse community sample. Journal of Consulting and Clinical Psychology, 80(5), 842-849. https://doi.org/10.1037/a0029429

Hawton, K., \& Harriss, L. (2007). Deliberate self-harm in young people: characteristics and subsequent mortality in a 20 year cohort of patients presenting to hospital. Journal of Clinical Psychiatry, 68(10), 1574-1583.

Ireland, J. L., \& Quinn, K. (2007). Officer attitudes towards adult male prisoners who selfharm: development of an attitudinal measure and investigation of sex differences. Aggressive Behavior, 33(1), 63-72. https://doi.org/10.1002/ab.20168

Joiner, T. (2005). Why people die by suicide. Cambridge, MA: Harvard University Press. Joiner T., \& Van Orden K. A. (2008). The interpersonal psychological theory of suicidal behavior indicates specific and crucial psychotherapeutic targets. International Journal of Cognitive Therapy, 1(1), 80-89. https://doi.org/10.1521/ijct.2008.1.1.80

Karasouli, E., Owens, D., Latchford, G., \& Kelley, R. (2015). Suicide after nonfatal selfharm: A population case-control study examining hospital care and patient 
FACTORS RELEVANT TO SELF-INJURIOUS BEHAVIOUR

characteristics. Crisis: The Journal of Crisis Intervention and Suicide Prevention, 36(1), 65-70. https://doi.org/10.1027/0227-5910/a000285

Keeney, S., Hasson, F., \& McKenna, H. (2006). Consulting the oracle: Ten lessons from using the Delphi technique in nursing research. Journal of Advances in Nursing, 52(2), 205-212. https://doi.org/10.1111/j.1365-2648.2006.03716.x

Klonsky, D. E., May, A. M., \& Glenn, C. R. (2013). The relationship between nonsuicidal self-injury and attempted suicide: Converging evidence from four samples. Journal of Abnormal Psychology, 122(1), 231-237. https://doi.org/10.1037/a0030278

Lewis, S. P., Rosenrot, S. A., \& Santor, D. A. (2011). An integrated model of self-harm: Identifying predictors of intent. Canadian Journal of Behavioural Science, 43(1), 20 29. https://doi.org/10.1037/a0022076

Lewis, S.P., \& Hasking, P. (2019). Putting the "self" in self-injury research: Inclusion of people with lived experience in the research process. Psychiatric Services, 70(11), November, 1058 -1060. https://doi.org/10.1176/appi.ps.201800488

Mann, J., Apter, A., \& Bertolote, J. (2005). Suicide prevention strategies: A systematic review. The Journal of the American Medical Association, 294(16), 2064-2074. https://doi.org/10.1001/jama.294.16.2064

McAllister, M., Creedy, D., Moyle, W., \& Farrugia, C. (2002). Nurses' attitudes towards clients who self-harm. Journal of Advanced Nursing, 40(5), 578-586. https://doi.org/10.1046/j.1365-2648.2002.02412.x

Morgan, H. G., \& Priest, P. (1991). Suicide and other unexpected deaths among psychiatric in-patients. The Bristol confidential inquiry. The British Journal of Psychiatry, 158(3), 386-374. https://doi.org/10.1192/bjp.158.3.368 
FACTORS RELEVANT TO SELF-INJURIOUS BEHAVIOUR

O'Connor, R. C., \& Armitage, C. J. (2003). Theory of planned behaviour and parasuicide: An exploratory study. Current Psychology, 22(3), 196-205. https://doi.org/10.1007/s12144-003-1016-4

O'Connor, R. C., Armitage, C. J., \& Gray, L. (2006). The role of clinical and social cognitive variables in parasuicide. British Journal of Clinical Psychology, 45(4), 465-481. https://doi.org/10.1348/014466505X82315

Sandy, P., \& Shaw, D. (2012). Attitudes of mental health nurses to self-harm in secure forensic settings: A multi method phenomenological investigation. Journal of Medicine and Medical Science Research, 1(4), 63-75.

Selby, E. A., \& Joiner, T. E. (2009). Cascades of emotion: The emergence of borderline personality disorder from emotional and behavioural dysregulation. Review of General Psychology, 13(3), 219-229. https://doi.org/10.1037/a0015687

Skulmoski, G. J., Hartman, F. T., \& Krahn, J. (2007). The Delphi method for graduate research. Journal of Information Technology Education, 6, 1-21.

White, J., Leggett, J., \& Beech, A. (1999). The incidence of self-harming behaviour in the male population of a medium secure psychiatric hospital. The Journal of Forensic Psychiatry, 10(1), 59-68. https://doi.org/10.1080/09585189908402139

\section{What does this paper contribute to the wider clinical community?}

- Important variables to account for in patient self-injurious behaviour are anticipated affect, capacity to harm and perceived burdensomeness.

- Patient intention and their perceived behavioural control is critical.

- Staff place emphasis on patients being in control of their self-injurious behaviour. 
FACTORS RELEVANT TO SELF-INJURIOUS BEHAVIOUR

Table 1

Theory-driven Measure of Self-Injurious Behaviour Engagement (TM-SIBE) version 1.

Percentage endorsement for items professional experts considered important to capture.

\begin{tabular}{|c|c|c|}
\hline Items & $\begin{array}{l}\text { Considered } \\
\text { essential } \\
(\mathbf{n}=\mathbf{2 0})\end{array}$ & $\begin{array}{l}\text { Considered } \\
\text { important } \\
(n=20)\end{array}$ \\
\hline Injuring myself has been a common behaviour for me in the past ${ }^{\mathrm{a}}$ & $80 \%$ & $20 \%$ \\
\hline $\begin{array}{l}\text { Injuring myself now would be easier than the first time I injured } \\
\text { myself }^{\text {a }}\end{array}$ & $35 \%$ & $60 \%$ \\
\hline Injuring myself would provide relief from my current symptoms ${ }^{a}$ & $80 \%$ & $15 \%$ \\
\hline Do you have an understanding of the reasons you injure yourself? ${ }^{b}$ & $70 \%$ & $30 \%$ \\
\hline Injuring myself would be pleasant......unpleasant ${ }^{\mathrm{c}}$ & $40 \%$ & $40 \%$ \\
\hline Rate the ease of self-injury for you ${ }^{\mathrm{d}}$ & $50 \%$ & $50 \%$ \\
\hline $\begin{array}{l}\text { Rate the strength of your intention to injure yourself in the next } \\
\text { week }^{\mathrm{e}}\end{array}$ & $75 \%$ & $20 \%$ \\
\hline Do you have any plans for how you would injure yourself? ${ }^{b}$ & $95 \%$ & $5 \%$ \\
\hline I have positive things in my life ${ }^{\mathrm{f}}$ & $35 \%$ & $60 \%$ \\
\hline Does the thought of suicide make you feel (relaxed vs. frightened) ${ }^{g}$ & $25 \%$ & $55 \%$ \\
\hline $\begin{array}{l}\text { Do you know the reasons behind your self-injury/thoughts of self- } \\
\text { injury? }^{\text {b }}\end{array}$ & $45 \%$ & $55 \%$ \\
\hline It is in my control if I injure myself ${ }^{b}$ & $65 \%$ & $35 \%$ \\
\hline I intend to injure myself ${ }^{b}$ & $75 \%$ & $25 \%$ \\
\hline
\end{tabular}


After injuring yourself would you be more likely to feel (relieved $70 \%$

$25 \%$

vs. guilty) ${ }^{\mathrm{h}}$.

I feel part of a valued group of people (e.g. friends, family, 10\% $75 \%$

colleagues, people around you $)^{\mathrm{b}}$

Have you found everything getting on top of you ${ }^{\mathrm{b}}$

$20 \%$

$70 \%$

My current environment is having a [negative/positive] impact on 20\%

$70 \%$

my thoughts about self-injury ${ }^{i}$

I want support to explore other ways to cope with thoughts and $65 \%$

$35 \%$

emotions $^{\mathrm{b}}$

Footnote: Anchors on final rating scale were ${ }^{a}$ Agree vs. Disagree; ${ }^{b}$ Definitely vs. Definitely Not; ${ }^{c}$ Pleasant vs.

Unpleasant; ${ }^{\mathrm{d}}$ Easy vs. Difficult; ${ }^{\mathrm{e} S t r o n g}$ vs. Weak; ${ }^{\mathrm{f}}$ Agree vs. Disagree; ${ }^{\mathrm{g}}$ Relaxed vs. Frightened; ${ }^{\mathrm{h}}$ Relieved vs.

Guilty; ${ }^{i}$ Negative vs. Positive. 
FACTORS RELEVANT TO SELF-INJURIOUS BEHAVIOUR

Table 2

Item loadings of Theory-driven Measure of Self-Injurious Behaviour Engagement (TM-SIBE-

CV) - Client Version. $(n=76)$.

\begin{tabular}{|c|c|c|}
\hline Item & $\begin{array}{l}\text { Factor 1: Increased } \\
\text { capacity and positive } \\
\text { belief in affective value } \\
\text { of self-harm } \\
\text { 34.5\% variance } \\
\text { Loadings } \\
\text { Factor mean* } \\
\text { 17.9/11.2sd }\end{array}$ & $\begin{array}{l}\text { Factor 2: Intention to } \\
\text { self-harm and feeling } \\
\text { valued } \\
11.5 \% \text { variance } \\
\text { Loadings } \\
\text { Factor mean* } \\
9.5 / 5.7 \mathrm{sd}\end{array}$ \\
\hline $\begin{array}{l}\text { Injuring myself would provide relief } \\
\text { from my current symptoms of } \\
\text { discomfort. }\end{array}$ & .81 & - \\
\hline $\begin{array}{l}\text { Injuring myself would be } \\
\text { pleasant/unpleasant. }\end{array}$ & .75 & - \\
\hline $\begin{array}{l}\text { Injuring myself now would be easier than } \\
\text { the first time I injured myself. }\end{array}$ & .73 & - \\
\hline $\begin{array}{l}\text { Injuring myself has been a common } \\
\text { behaviour for me in the past. }\end{array}$ & .73 & - \\
\hline $\begin{array}{l}\text { After injuring yourself would you be } \\
\text { more likely to feel relieved/guilty. }\end{array}$ & .725 & - \\
\hline
\end{tabular}




\begin{tabular}{|l|l|l|}
\hline $\begin{array}{l}\text { How easy would it be for you to self- } \\
\text { injure? }\end{array}$ & .53 & - \\
\hline $\begin{array}{l}\text { I feel part of a valued group of people } \\
\text { (e.g. friends, family, colleagues, people }\end{array}$ & - & .75 \\
around me). & - & .60 \\
\hline $\begin{array}{l}\text { What is the strength of your intention to } \\
\text { injure yourself in the next week? }\end{array}$ & - & .52 \\
\hline $\begin{array}{l}\text { Does the thought of trying to commit } \\
\text { suicide make you feel } \\
\text { relaxed/frightened? }\end{array}$ & - & \\
\hline I intend to injure myself. & - & .506 \\
\hline Do you have any plans for how you \\
would injure yourself?
\end{tabular}

*Factor scores calculated using items that score above .50 
FACTORS RELEVANT TO SELF-INJURIOUS BEHAVIOUR

Table 3

Item loadings of Theory-driven Measure of Self-Injurious Behaviour Engagement-staff version $(T M-S I B E-S v) .(n=100)$.

\begin{tabular}{|c|c|c|c|}
\hline Item & $\begin{array}{l}\text { Factor 1: } \\
\text { Patients in } \\
\text { control, } \\
\text { planning for } \\
\text { and intending } \\
\text { self-injurious } \\
\text { behaviour } \\
\text { 19.0\% variance } \\
\text { Loadings } \\
\text { Factor mean* } \\
12.8 / 3.37 \text { sd }\end{array}$ & $\begin{array}{l}\text { Factor 2: } \\
\text { Being valued } \\
\text { and coping } \\
\text { effectively } \\
\text { 13.6\% variance } \\
\text { Loadings } \\
\text { Factor mean* } \\
11.0 / 2.8 \mathrm{sd}\end{array}$ & $\begin{array}{l}\text { 10.9\% variance } \\
\text { Loadings } \\
\text { Factor mean* } \\
11.3 / 3.34 \mathrm{sd}\end{array}$ \\
\hline $\begin{array}{l}\text { Patients have control over whether } \\
\text { or not they decide to injure } \\
\text { themselves }\end{array}$ & .64 & -.54 & - \\
\hline $\begin{array}{l}\text { Patients know the reasons behind } \\
\text { their self-injury/thoughts of self- } \\
\text { injury }\end{array}$ & .63 & - & - \\
\hline $\begin{array}{l}\text { Patients have plans for how they } \\
\text { would injure themselves }\end{array}$ & .54 & - & - \\
\hline
\end{tabular}




\begin{tabular}{|c|c|c|c|}
\hline $\begin{array}{l}\text { Patients intend to injure } \\
\text { themselves }\end{array}$ & .52 & - & - \\
\hline $\begin{array}{l}\text { After injuring, a patient would be } \\
\text { more likely to feel relieved/guilty }\end{array}$ & .47 & - & - \\
\hline $\begin{array}{l}\text { Patients do not have an } \\
\text { understanding of the reasons why } \\
\text { they injure themselves** }\end{array}$ & -.41 & - & - \\
\hline $\begin{array}{l}\text { Patients feel part of a valued group } \\
\text { of people (e.g. friends, those } \\
\text { around them) }\end{array}$ & - & .65 & - \\
\hline $\begin{array}{l}\text { Patients often find everything } \\
\text { getting on top of them** }\end{array}$ & - & .54 & - \\
\hline $\begin{array}{l}\text { Patients have positive things in } \\
\text { their life }\end{array}$ & - & .54 & - \\
\hline $\begin{array}{l}\text { The current environment has the } \\
\text { following impact on a patient's } \\
\text { thoughts about self-injury } \\
\text { (negative/positive) }\end{array}$ & - & .47 & - \\
\hline $\begin{array}{l}\text { Self-injury for patients would be } \\
\text { pleasant/unpleasant }\end{array}$ & - & - & .77 \\
\hline $\begin{array}{l}\text { Self-injury for patients would be } \\
\text { easy/hard** }\end{array}$ & - & - & .73 \\
\hline
\end{tabular}




\begin{tabular}{|l|l|l|l|}
\hline $\begin{array}{l}\text { For patients, injuring themselves is } \\
\text { easier after the first time they }\end{array}$ & - & - & .50 \\
injure themselves & - & - & \\
\hline $\begin{array}{l}\text { Self-injury provides relief for } \\
\text { patients from their current }\end{array}$ & & & \\
symptoms of discomfort & & & \\
\hline
\end{tabular}

*Factor scores calculated using items that score above .50

**reverse scored. 